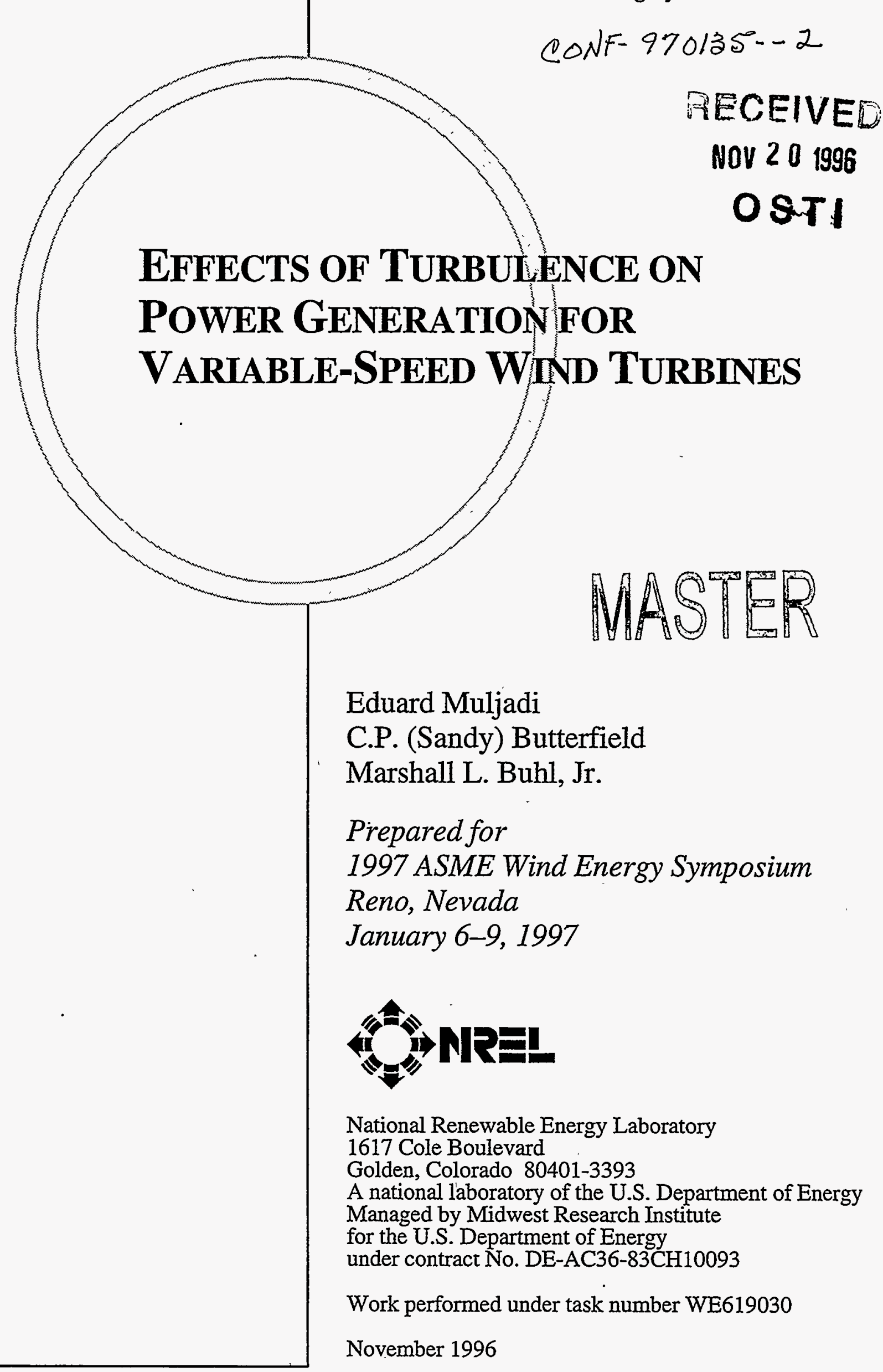




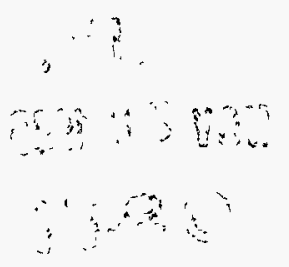

NOTICE

This report was prepared as an account of work sponsored by an agency of the United States government. Neither the United States government nor any agency thereof, nor any of their employees, makes any warranty, express or implied, or assumes any legal liability or responsibility for the accuracy, completeness, or usefulness of any information, apparatus, product, or process disclosed, or represents that its use would not infringe privately owned rights. Reference herein to any specific commercial product, process, or service by trade name, trademark, manufacturer, or otherwise does not necessarily constitute or imply its endorsement, recommendation, or favoring by the United States govemment or any agency thereof. The views and opinions of authors expressed herein do not necessarily state or reflect those of the United States government or any agency thereof.

Available to DOE and DOE contractors from:

Office of Scientific and Technical Information (OSTI)

P.O. Box 62

Oak Ridge, TN 37831

Prices available by calling (423) 576-8401 .

Available to the public from:

National Technical Information Service (NTIS)

U.S. Department of Commerce

5285 Port Royal Road

Springfield, VA 22161

(703) $487-4650$ 


\section{DISCLAIMER}

Portions of this document may be illegible in electronic image products. Images are produced from the best available original document. 


\title{
EFFECTS OF TURBULENCE ON POWER GENERATION FOR VARIABLE-SPEED WIND TURBINES
}

\author{
Eduard Muljadi \\ Electrical Systems Engineer \\ C.P. (Sandy) Butterfield \\ Senior Engineer \\ Marshall L. Buhl, Jr. \\ Senior Mechanical Engineer \\ National Renewable Energy Laboratory \\ Golden, Colorado
}

\begin{abstract}
One of the primary advantages of variable-speed wind turbines over fixed-speed turbines should be improved aerodynamic efficiency. With variable-speed generation, in order to maintain a constant ratio of wind speed to tip speed, the wind turbine changes rotor speed as the wind speed changes.

In this paper we compare a stall-controlled, variablespeed wind turbine to a fixed-speed turbine. The focus of this paper is to investigate the effects of variable speed on energy capture and its ability to control peak power. We also show the impact of turbulence on energy capture in moderate winds.

In this report, we use a dynamic simulator to apply different winds to a wind turbine model. This model incorporates typical inertial and aerodynamic performance characteristics.

From this study we found a control strategy that makes it possible to operate a stall-controlled turbine using variable speed to optimize energy capture and to control peak power. We also found that turbulence does not have a significant impact on energy capture.

\section{INTRODUCTION}

The development of wind turbine (WT) power generation has intensified during the past ten years. The global market for the electrical power generated by wind turbines has been increasing steadily; this directly pushes wind technology into a more competitive arena.

Variable-speed (VS) WT generation has been gaining momentum as shown by the number of companies joining the variable-speed WT market. Conventional wisdom states that VS wind turbines have a better
\end{abstract}

This paper is declared a work of the U.S. Government and is not subject to copyright protection in the United States. energy capture and lower loads. To assess the performance of VS wind turbines, we will compare the energy capture and peak power of a fixed-speed (FS) turbine to that of a VS turbine.

Many papers written on variable speed focus only on optimizing energy capture $e^{1.2}$ while others concentrate on the generator design of variable-speed wind turbines, 3 .

Although VS wind turbines can be controlled in many different ways, this paper will assess only constant pitch control schemes and present the possible problems we discover from this analysis. We lump other methods of aerodynamic control such as ailerons into the variablepitch category. While several papers examine VS with variable-pitch control ${ }^{5,6}$, it is interesting to investigate VS with fixed pitch. Our intention is to seek a solution that both optimizes the energy capture and minimizes the peak power requirement for the generator and power converter. If such a control system can be implemented with benefits close to that of VS with variable pitch, the investment, operation, and maintenance costs can be tremendously reduced due to the simplicity of needing no pitch control system. This economic advantage may be a key point for reducing the cost of energy and for market expansion. Figure 1 shows the two systems under consideration.

\section{BACKGROUND}

\section{Objectives}

For this project, we modeled a generic, 3-bladed wind turbine using typical physical dimensions and aerodynamic characteristics. We used WT_Perf (a derivative of PROPPC ${ }^{7}$ ) to generate a $C_{p}-\lambda$ curve, where $C_{p}$ is the

- WT_Perf is available for testing purposes and can be found on our web site at http://nwtc.nrel.gov/html_docs/codes.html 


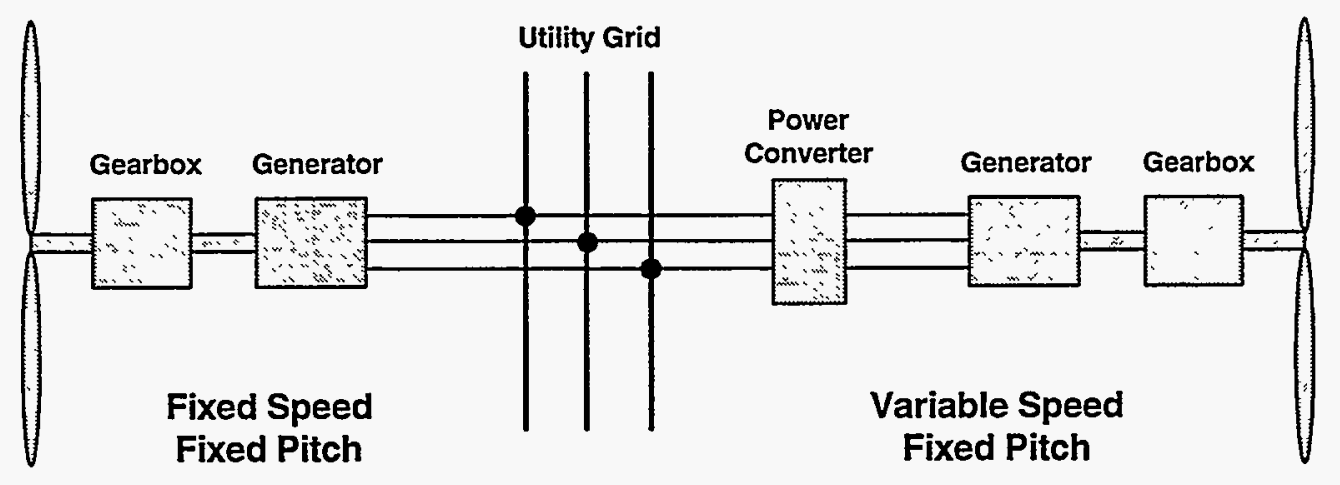

Figure 1. Fixed-speed versus variable-speed wind-turbine power generation

power coefficient and $\lambda$ is the ratio of tip speed to wind speed. Our primary objective was to determine the effects of the turbulence on the wind turbine performance and energy capture. When comparing the two types of turbines (VS versus FS), we chose the rotor-speed limit to optimize the annual energy production for a FS wind turbine at a $5.8 \mathrm{~m} / \mathrm{s}$ wind-speed site.

The operation of the wind turbine in FS mode is a very simple case that we used as a baseline. We also used two VS algorithms. The first follows (with increasing wind speed) the maximum $C_{p}$ up to the rotorspeed limit before forcing stall by reducing rotor speed. We call it the "Maximum $C_{p}$ " algorithm. It turns out that using this algorithm works well at moderate wind speeds, but at high wind speeds, it has a problem with high power excursions.

To address the power excursions that occur at high wind speeds, we developed a second control method. It departs from the maximum $C_{p}$ at a lower rotor speed to force stall at a lower wind speed. We call it the "Early Stall" algorithm. It should reduce the power excursions that occur at high wind speeds. We now have two main objectives. One objective is to optimize the energy capture at moderate wind speeds, because they account for most of the annual energy production. The other is to minimize the power excursions at higher wind speeds.

\section{Wind Input Data}

Neil Kelley of the National Wind Technology Center generated the artificial wind data we used in our analyses. He used SNLWIND-3D ${ }^{8}$ to produce the 10 -minute time series of three-component, two-dimensional winds. For various wind speeds, he created winds that are similar to those seen in smooth conditions like the Great Plains and in the rough turbulence of a wind farm in San Gorgonio, California. The surface roughness used for the smooth cases was 0.010 and it was 0.264 for the rough cases. The mean u-component of the wind files varied from 6 to $18 \mathrm{~m} / \mathrm{s}$.

We converted these wind files to a form usable by our simulators with a program we wrote called $\operatorname{Sim} 2 \mathrm{HH}$. This program used only the hub-height data points for each component and converted the u- and v-components to horizontal wind speed and direction. Examples of the wind input for rough and smooth cases are given in Figure 2.

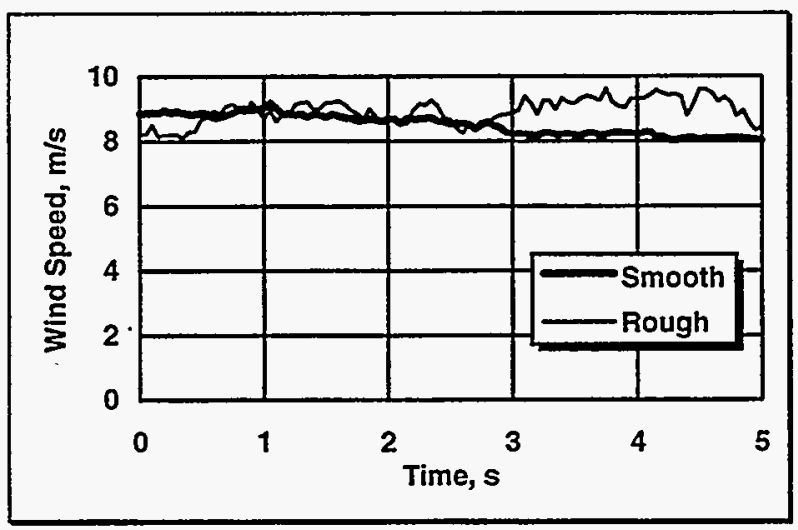

Figure 2. Time histories of example winds

Our simulations used the horizontal wind speed data for input, but ignored the wind direction data. Ideally, we should have used only the u-component of the winds, but we did not think it merited the effort to reprocess the wind data for this study. This is essentially the assumption that the turbine can track the wind with zero yaw error.

\section{METHODS OF CONTROL}

\section{Fixed Speed}

The simplest wind turbine architecture is the FS, fixed-pitch wind turbine. It uses stall control to regulate 
power. Its power versus wind speed is shown in Figure 3. There we see that at higher rotor speeds $(\Omega)$, the rotor will generate a higher peak power and that power occurs at higher wind speeds. We will explain this figure further in the section on variable speed.

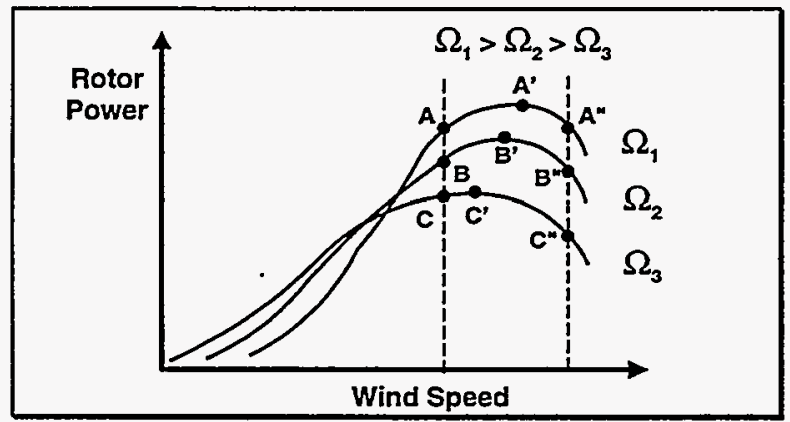

Figure 3. Rotor power versus wind speed at different rotor speeds

Different rotor speeds affect the operating point of the wind turbine on the $C_{p}-\lambda$ curve. We show the operating $C_{p}$ for two different rotor speeds in Figure 4. For the 28.6-rpm rotor, the operating $C_{p}$ varies from a low $C_{p}$ at low wind speeds to a higher $C_{p}$ at higher wind speeds. For the 34.8-rpm rotor, the operating $C_{p}$ varies from a higher $C_{p}$ at low wind speeds, to a lower $C_{p}$ at higher wind speeds.

The $28.6 \mathrm{rpm}$ rotor will produce more energy, because at moderate wind speeds, the operating $C_{p}$ is higher than for one rotating at $34 \mathrm{rpm}$. At high wind speeds, where the power should be limited, the slower rotor operates at a lower $C_{p}$ because it is stalled. The faster rotor behaves in the opposite way. At moderate wind speeds, $C_{p}$ is low, while in higher winds, $C_{p}$ is high. The rotor needs to have the highest average $C_{p}$ occur at the most productive wind speed, which varies from site to site.
We chose $28.6 \mathrm{rpm}$, as it is optimal for this turbine at a $5.8 \mathrm{~m} / \mathrm{s}$ site.

\section{Variable Speed}

Ideal conditions. Ideally, the wind speed would vary slowly and the rotor inertia would be negligible. Then, when the wind speed changes, the rotor could change speed instantaneously.

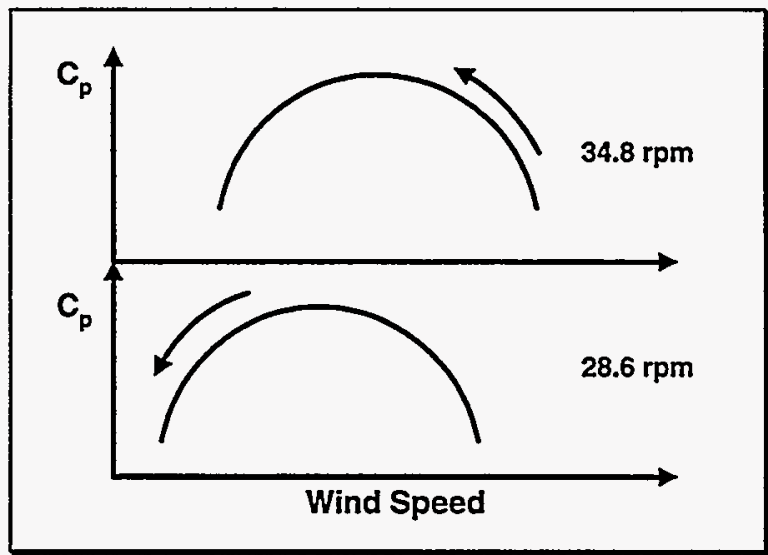

Figure 4. The operating $C_{p}$ for two different rotor speeds

We illustrate the Maximum $C_{p}$ algorithm, which works well for this ideal, in Figure 5. The algorithm has three distinct regions. At low to moderate wind speeds (point $O$ to point $B$ ), the control system commands the generator to follow the maximum $C_{p}$ at any rotor speed. We call this the Constant $C_{p}$ region.

As the wind speed increases and the rotor speed reaches its limit, the control system requests a fixed speed. At fixed speed (point $B$ to point $C$ ), with increasing wind speed, the rotor power keeps increasing

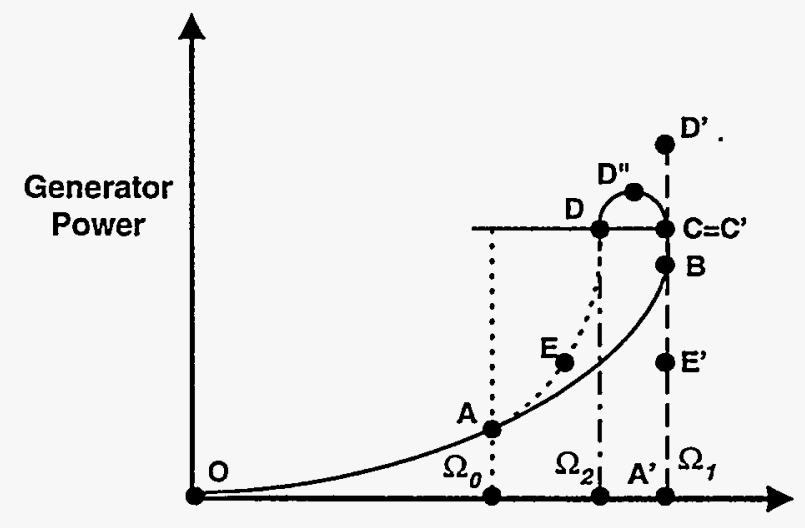

Rotor Speed, $\Omega$

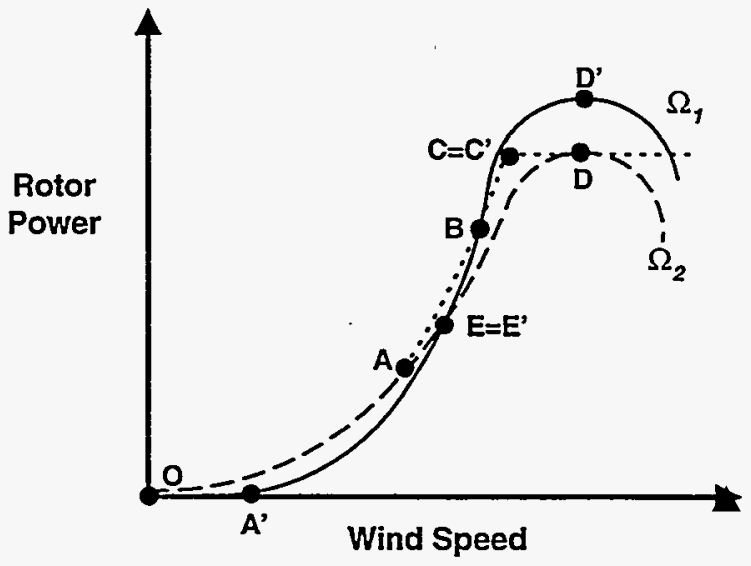

Figure 5. (a) Generator power and (b) rotor power for two variable-speed algorithms 
(at a $C_{p}$ lower than $C_{p, m a x}$ ) and eventually reaches its maximum power limit. This is the Constant Speed region, where the $C_{p}$ starts to slide down from $C_{p, \text { max }}$.

After the power reaches its limit, we reduce the rotor speed to further decrease $C_{p}$ (point $C$ to point $D$ ). We call this the Power Limit region. As the wind speed increases, we must reduce the rotor speed to keep the rotor power below its power limit.

Trpical wind conditions. In the real world, wind speed changes quickly and the inertia of the wind turbine resists instantaneous change. When the rotor speed slows, the electrical systems (generator and power converter) must absorb the kinetic energy from the rotor.

The following simple dynamic equation describes the interaction between generator and wind turbine:

$$
J \frac{d \Omega}{d t}=T_{r}-T_{g}
$$

where:

$J$ is the total inertia,

$T_{r}$ is the rotor torque,

$T_{g}$ is the generator torque, and

$\Omega$ is the mechanical rotor speed.

From this, one can see that a change in wind speed affects the rotor torque and we can conclude the following:

- In the fixed speed region, controlling the generator torque to be exactly equal to the rotor torque will keep the rotor speed constant. Thus, the generator converts all the power the rotor provides. The rotor torque depends on the wind speed and the operating $C_{p}$.
In the constant $C_{p}$ region, controlling the rotor speed to follow the wind speed requires that

$$
T_{g}=T_{r}-J \frac{d \Omega}{d t}
$$

where

$$
T_{r}=1 / 2 \rho C_{p, \max } A \Omega^{2}\left(\frac{R}{\lambda_{\text {targ }}}\right)^{3}
$$

and

$\rho$ is the air density,

$A$ is the rotor swept area,

$R$ is the rotor radius, and

$\lambda_{\text {rarg }}$ is the target tip-speed ratio.

Thus, to operate at exactly $C_{p, \max }$, the inertia term should not be neglected. If the inertia term is neglected (if we assume that the effect of rotor inertia is negligible), the operating $C_{p}$ will not be exactly at $C_{p, \max }$. In this paper, we compute the commanded generator torque using Equation 3; thus, we do neglect the inertia effect. Apparently, as shown in Figure 11, the performance of the wind turbine is very close to ideal-even though the inertia term is neglected from the commanded torque calculation.

- When limiting power, reducing the rotor speed at constant wind speed will generate the power and torque profile shown in Figure 6.

We show the generator torque required to reduce the rotor speed as a dotted line in the right half of Figure 6. This corresponds to the generator power required to reduce the rotor speed (dotted line in the left half of Figure 6).

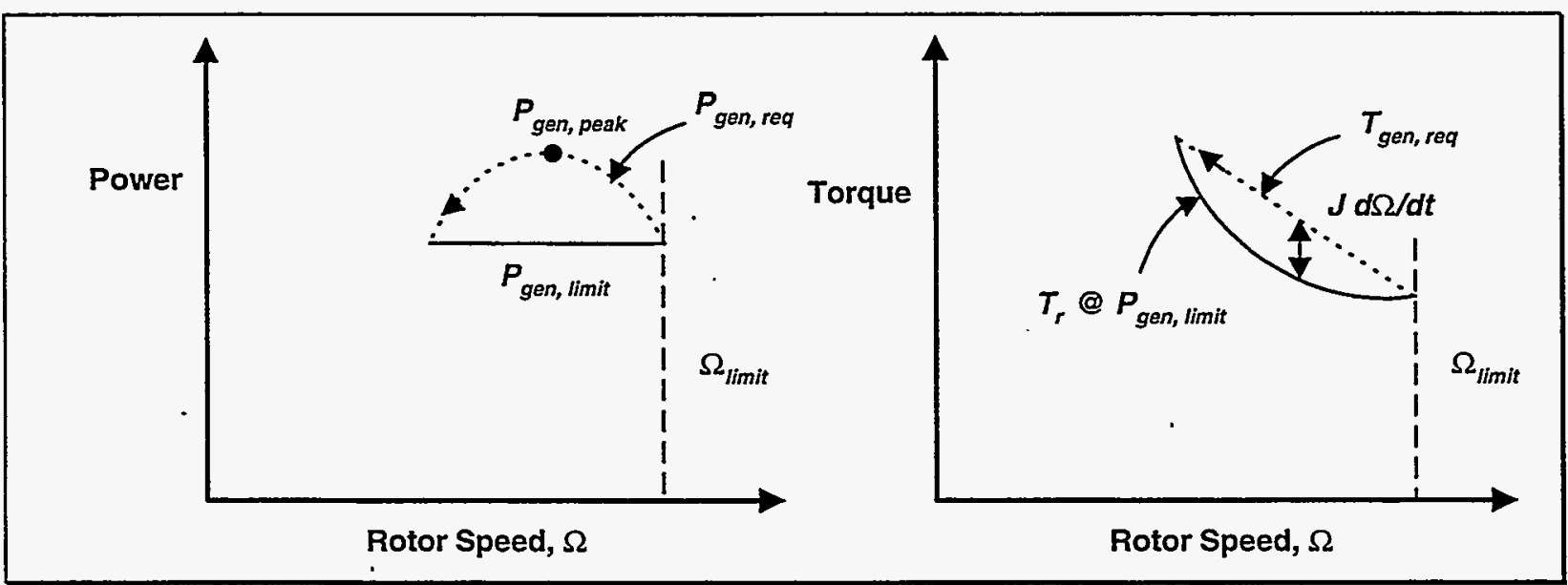

Figure 6. Power and torque in the power limiting region 
We also show the peak generator power that can be used to size the generator and the power converter. Several factors affect this peak. They are the wind speed, the rate of deceleration, the rotor inertia, and the rotor speed limit.

Impacts on Peak Generator Power. For the constant wind speed case, the system will follow the dotted line in Figure 3 from point $A$, through $B$, to $C$ as the rotor slows down from $\Omega_{J}$ to $\Omega_{3}$. During the move downward, the rate of rotational deceleration will have an impact on the peak generator power. The greater the deceleration or inertia, the greater the peak generator power will be. This is because the $J d \Omega / d t$ term is added to the rotor power to produce the generator power.

If the wind speed increases rapidly compared to the rotor deceleration, the rotor power will essentially follow the $\Omega_{l}$ curve of Figure 3. The operating point will move along point $A^{\prime}$ and $A^{\prime \prime}$. Thus, the peak power of the generator will be $A^{\prime}$.

The rotor-speed limit also impacts peak power. Suppose the rate of deceleration is very low and the limit on rotor speed is $\Omega_{l}$, the peak power will be $A^{\prime}$. If, instead, the rotor-speed limit is $\Omega_{2}$, the peak power will drop to $B^{\prime}$. Thus, setting a lower rotor-speed limit will reduce peak power.

\section{Second Variable-Speed Algorithm}

The Maximum $C_{p}$ algorithm follows the power-speed characteristics specified by the precomputed generator power versus rotor-speed map. However, the peak generator power is determined by many factors as described above.

The rotor torque depends only on the wind speed and the power coefficient; it is not controllable. The generator torque, however, depends on the generator controls, so it is controllable. When there is enough wind, the rotor torque increases continuously and, for fixed speed, there is a peak torque or peak power that the rotor produces. However, the generator torque can only increase up to its electrical limit. As long as the rotor torque is higher than the generator torque, the acceleration is positive and the rotor speed increases. Keep in mind that as the rotor speed increases, the peak generator power also increases as shown in Figure 3 above. One strategy to limit the torque spikes that might occur is to change the schedule for power versus rotor speed.

We illustrate the Early Stall algorithm in Figure 5a. We modified the power-speed profile to reduce the power spikes that occurred for the Maximum $C_{p}$ algorithm. The transition from point $A$ to point $D$ is made by departing from the maximum $C_{p}$ at an earlier rotor speed than the normal speed limit (point $B$ ). The curve $O A C$ is the path for maximum $C_{p}$ and the curve $A E D$ is the path for this Early Stall algorithm.

Rotor power. We show the rotor power as a function of wind speed in Figure 5b. The FS operation is along the solid line $A^{\prime} E^{\prime} D^{\prime}$. The Maximum algorithm follows the path $O A B C D$, where the $B C D$ portion is allowed to diverge from $C_{p, \text { max }}$ by decreasing the rotor speed. The Early Stall algorithm follows the curve $O A E D$. The maximum $C_{p}$ path follows $O A B$, which will generate more power than the FS operation $\left(A^{\prime} E^{\prime} B\right)$. The area in $O A^{\prime} E^{\prime} B A O$ is the gain of the Maximum $C_{p}$ over the FS operation. The gain of the Early Stall algorithm over FS operation is $O A E^{\prime} A^{\prime} O$. Note, also, that the maximum power is reduced from $D^{\prime}$ to $D$.

Power limit in the high wind-speed region. At high wind speeds, the generator power exhibits different characteristics for different methods of control. A FS turbine generates the highest power with the peak occurring at point $D$ as we show in Figure 5a. With VS control, one can limit the power to point $D^{\prime}$ by reducing rotor speed to stall it. However, in reality, the generator power must be increased to slow the rotor to stall it and absorb the kinetic energy. With the Early Stall algorithm, the rotor operates off-peak in part of the

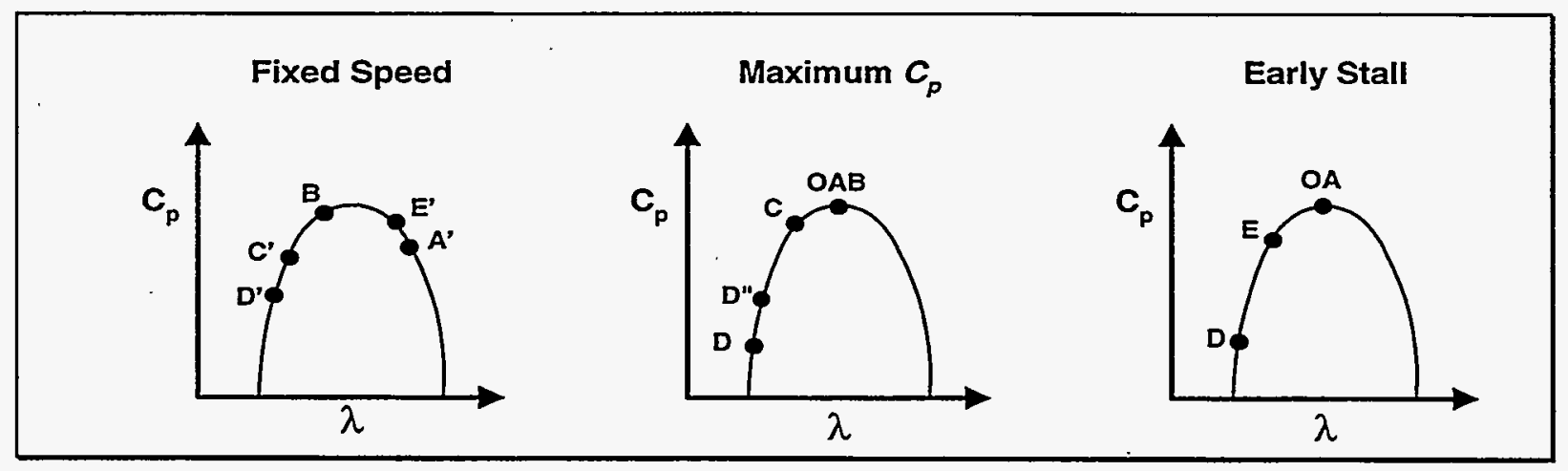

Figure 7. Power coefficients for different control algorithms 
operation (from point $A$ to point $D$ ). This results in a maximum rotor speed that is lower than the rotor-speed limit.

We show $C_{p}$ for three different control methods in Figure 7. In this plot, the operating points shown correspond to those in Figure 5. For FS operation, one cannot control the power coefficient; the tip-speed ratio must follow the wind speed.

For the Maximum $C_{p}$ algorithm, $C_{p}$ is held at its maximum for the path $O A B$. From point $B$ to point $D$, the operating $C_{p}$ is less than the maximum. Keep in mind that during the process to reduce the rotor speed from $\Omega_{3}$ to $\Omega_{2}$, there are chances that the wind speed may increase quickly and the generated power (Figure 5a) could be as high as point $D^{\prime}$. This is the power the generator and converter must process; thus, it determines the power rating of the generator and the power converter.

The Early Stall algorithm modifies the demand for generator power as a function of rotor speed. The modification is made by multiplying part of the maximum $C_{p}$ path $(A E D)$ by an adjustable slope, $K$. The algorithm follows:

$$
\begin{aligned}
& P_{\text {targ }}=K \Omega^{3} \\
& \text { if }\left(\Omega \geq \Omega_{0}\right) \\
& \text { then } \\
& \qquad P_{\text {targ }}=P_{\text {targ }}\left(1+K \frac{\Omega-\Omega_{0}}{\Omega_{\text {limit }}-\Omega_{0}}\right) \\
& \text { endif }
\end{aligned}
$$

As an example, with $K=1, P_{\text {targ }}=2 K \omega_{m i}{ }^{3}$ at the rotor speed limit, $\Omega_{\text {linit. }}$. By changing the slope $K$, the generator loading can be adjusted. Thus, the slope and the $\omega_{m k 0}$ should be chosen based on the generator and the power converter rating.

Referring to Figure 5a, the operating $C_{p}$ of the Early Stall algorithm follows maximum $C_{p}$ from $O$ to $A$. Moving on from $A$ to $D$, the operating $C_{p}$ is below the maximum. The transition from point $A$ to point $D$ is done by loading the wind turbine above the target torque shown by Equation 2 and Equation 3. The rate of change of $C_{p}$ with respect to $\lambda$ (the sensitivity of operation) can be adjusted by choosing the appropriate value of $K$ in the algorithm shown above.

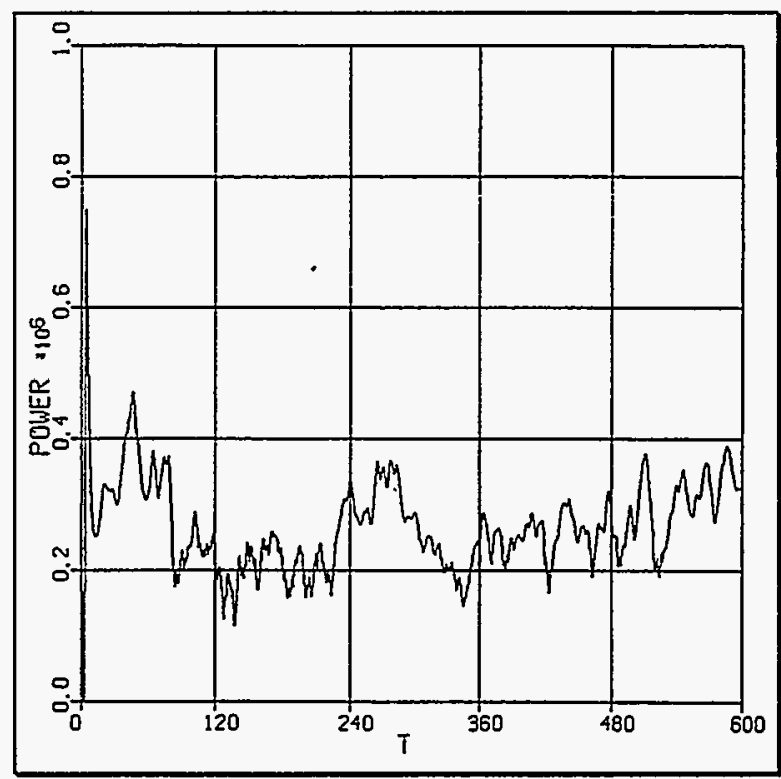

Figure 8. Power for smooth turbulence

\section{ANALYSIS ANDDISCUSSION}

\section{Power}

The peak generator power suggests the average power rating required for the generator and power converter. We ran our simulator for different wind speeds and degrees of turbulence. We compared the maximum power reached during the run to the rated power of the generator.

Figures 8 and 9 show time histories of the power generated for smooth and rough turbulence. The generated power is higher for the rough case. Because power is a cubic function of wind speed, a wind time history that has greater variability (more turbulence) for a given mean wind speed will have a higher average power; the cube of the mean is less than or equal to the mean of the cubes.

The variation of power generated by the wind turbine determines the size of the generator and the power converter. They should be sized to process the power at different wind speeds and levels of turbulence. For a comparison, we used the rough winds at both 6 and $14 \mathrm{~m} / \mathrm{s}$ average wind speeds for input to the simulator. Figure 10 shows the results of the simulations for a variety of control schemes.

Case K6_15 represents a case for the Early Stall algorithm with $\mathrm{K}=6$; the rotor speed at which the controller deviates from Cp, max is $15 \mathrm{rpm}$. From $15 \mathrm{rpm}$ to the rotor speed limit, the commanded generator power increases linearly such that at the rotor speed limit, the 


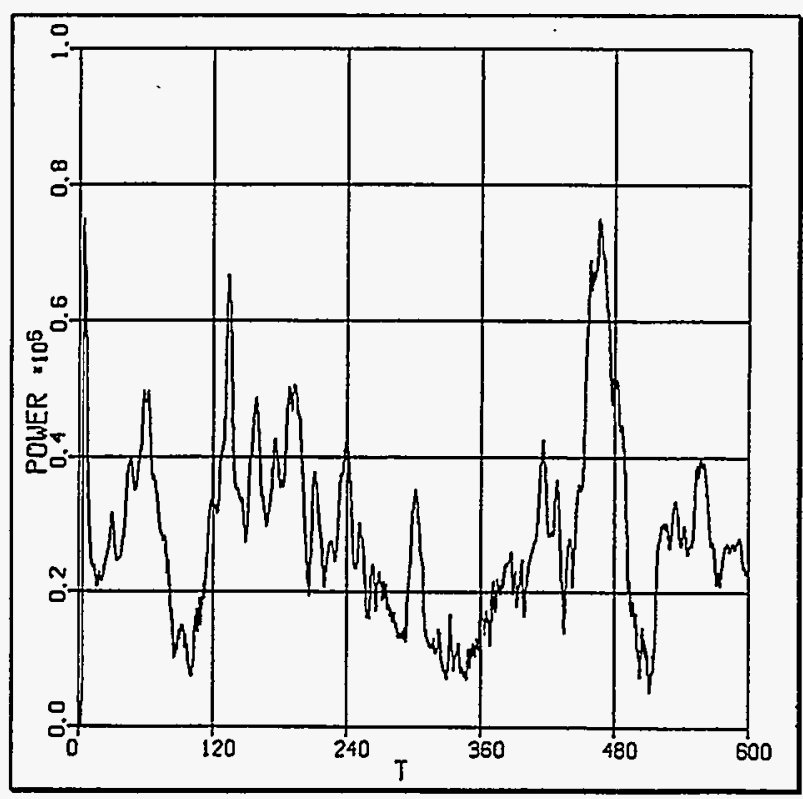

Figure 9. Power for rough turbulence

commanded generator power is seven $(6+1)$ times the old target power. The other cases follow the same convention.

Figure 10 shows that for the higher wind speeds, both the Maximum $C_{p}$ control system and the FS turbine exceed $1 \mathrm{MW}$ of output power. With the Early Stall algorithm, we adjusted the rotor speed to keep the maximum power below $1 \mathrm{MW}$. The lowest peak power for the second VS algorithm is case K6_15, where the power peaks at about $700 \mathrm{~kW}$. Because the lower wind-speed case is usually in the Constant $C_{p}$ region, there is little effect from the off-nominal nature of the Early Stall control system.

\section{Performance Ratio}

To gauge how well our control schemes help turbines capture energy, we created the performance ratio (PR). The PR is the ratio of actual shaft energy to optimal shaft energy:

$$
P R=\frac{\int P_{\text {actual }} d t}{\int P_{\text {targ }} d t}
$$

If the turbine always operates at peak power $\left(C_{p, \max }\right)$, the performance ratio will be unity. A lower performance ratio means the operating point deviates from the ideal. The performance ratio for VS shows a general trend. At lower wind speeds, we can operate near peak $C_{p}$. At higher wind speeds, the wind turbine must enter stall itself to prevent power excursions. Thus, the performance ratio and the average $C_{p}$ are lower at higher

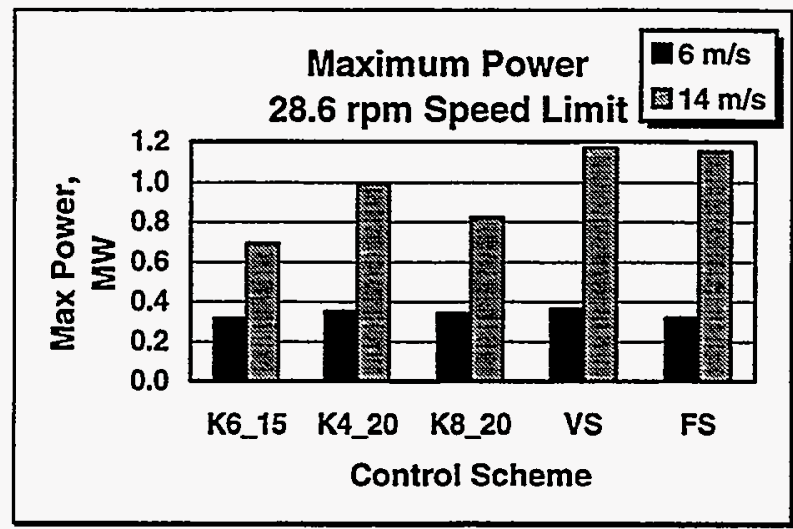

Figure 10. Maximum power for five control schemes

wind speeds. The rough wind speed cases do not deviate very far from the $C_{p, \max }$, which shows that variable speed tracks the wind speed very closely.

In Figure 11, we show the performance ratio for the same cases used for Figure 10. Note that choosing different control parameters has an impact on the performance ratio and the peak power. The high wind speed portion of the performance ratio plot is distorted because the cases that allowed the power to exceed the rating of the turbine generated more energy than those that did not.

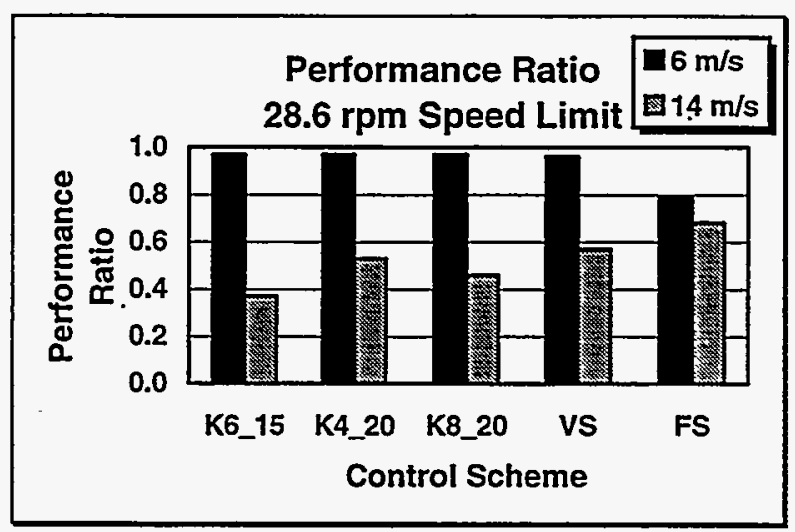

Figure 11. Performance ratios for five control schemes

In light winds, the variation between the VS algorithms is negligible. However, the PR for FS operation is significantly lower. This shows the advantage of being able to track the peak $C_{p}$ by varying the rotor speed.

In Figure 12, we show the PR for different levels of turbulence with VS control. Variable speed tracks the peak $C_{p}$ quite well for these conditions. Obviously, it is more difficult to track $C_{p, \text { max }}$ in rougher winds, but the difference is only a few percent. 


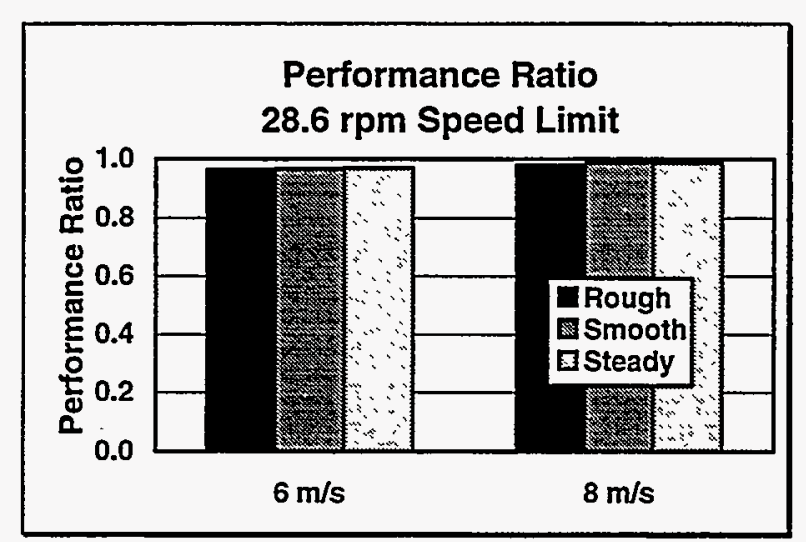

Figure 12. Performance ratio for different levels of turbulence

\section{Energy}

We computed the captured energy by integrating the power with respect to time We used energy calculations for our ten-minute simulations to compare the different control systems for various wind conditions. Figure 13 shows results for two wind speeds with rough turbulence. The trends for these results essentially mimic those for the PR calculation.

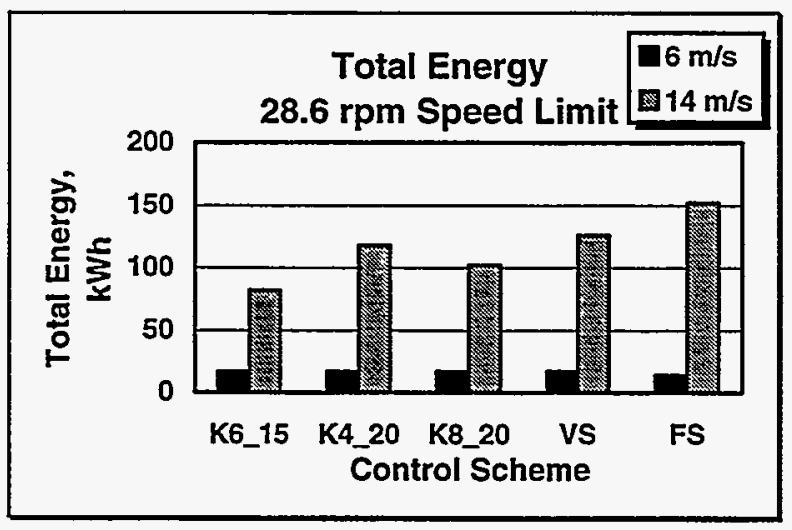

Figure 13. Energy captured during ten-minute simulations for five control schemes

At higher wind speeds $(14 \mathrm{~m} / \mathrm{s})$ the energy captured using VS is lower than for FS operation. However, the total annual energy contribution of high winds is very small. Thus from the view of annual energy production, the loss of energy captured during high winds is offset by gains at lower wind speeds. Energy capture for high wind speeds is lower for VS, because the wind turbine must operate stalled (below $C_{p, \text { max }}$ ). On the other hand, Figure 10 showed that a FS turbine or one using the Maximum $C_{p}$ algorithm will greatly exceed the power rating of the turbine.
For FS operation, the energy generated at lower wind speeds is lower than the energy generated by the VS operation. The choice of blade pitch and rotor speed or gear ratio affects the energy production for FS. Ideally, one would do so to maximize annual energy production for each site.

We show in Figure 14 that rough winds generate more energy than smooth or steady winds-especially when the wind turbine runs near $C_{p, \text { max }}$, where the $C_{p}-\lambda$ curve is fairly flat. High turbulence should not be a concern for energy capture, even though the operating performance ratio is lower for rough winds.

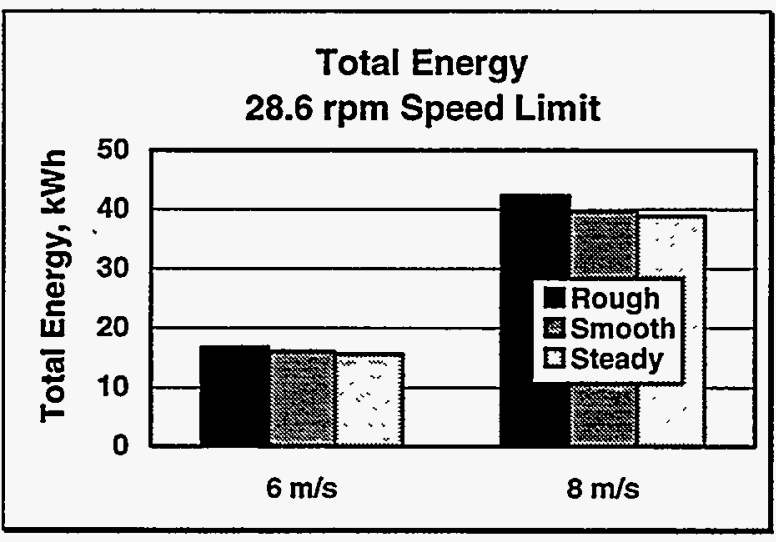

Figure 14. Effect of turbulence level on total energy capture

\section{CONCLUSIONS}

We simulated a fixed-pitch wind turbine operating in various turbulent winds. We compared fixed speed and variable-speed methods of operation. Considering our results, we draw the following conclusions:

- For a fixed-speed wind turbine, the choice of rotor speed has a strong impact on energy production, performance ratio, and the size of power excursions.

- Rough winds contain more energy than smooth or steady winds. If the $C_{p}-\lambda$ curve is reasonably flat, the generated energy will also be greater.

- For a variable-speed wind turbine, turbulence does not appreciably affect the performance ratio.

- For a wind turbine using the Early Stall method, at lower wind speeds (the most productive), the performance ratio is significantly lower than that for the other schemes. However, the energy capture is not significantly lower. At higher wind speeds (the most destructive), the peak power of the rotor is significantly lower than that for the other methods. The shape of the power-rotor-speed schedule 
controls the size of the power excursions. The trade-off between the energy production and the instantaneous peak power is an important one.

\section{ACKNOWLEDGMENTS}

We wish to thank Neil Kelley for providing the wind data sets used in this work and to Kristin Tromly for her timely editing.

We also thank our management at NREL and the Department of Energy for encouraging us and approving the time and tools we needed for this project. The U.S. Department of Energy supported this work under contract number DE-AC36-83CH10093.

\section{REFERENCES}

1. Beyer, H.G., Brümmer, H., Gerdes, G.J., Schmidt, W. "Optimization of hourly mean power output of wind energy converters with variable rotational speed using a dynamic model." Proceedings of the European Community Wind Energy Conference, Herning Congress Centre, Denmark, June 6-10, 1988. Bedford, England: H.S. Stephens \& Associates; pp. 605-610.

2. Muljadi, E., Butterfield C.P., Migliore, P. "Variable Speed Operation of Generators with RotorSpeed Feedback in Wind Power Applications." Wind Energy, Conference Proceedings of the ASME Wind Energy Symposium, Houston, TX, Jan. 29-Feb. 2, 1996. Book VIII, Vol. I. Houston, TX: PennWell Conferences \& Exhibitions; pp. 120-130.

3. Torrey, D., Childs S., de Haan S. "A VariableSpeed Wind Turbine Based on a Direct-Drive VariableReluctance Generator." Proceedings of Windpower '94, Minneapolis, MN, May 10-13, 1994. Washington, DC: American Wind Energy Association; pp. 513-522.

4. Fardoun, A.A., Fuchs E.F., Carlin P.W. "A Variable Speed, Direct Drive Transmission Wind Power Plant." Proceedings of Windpower '93, San Francisco, CA, July 12-16, 1993. Washington, DC: American Wind Energy Association; pp. 134-141.

5. Connor B., Leithead, W.E. "The effect of rotor characteristics on the control of pitch regulated variable speed wind turbines." Wind Energy Conversion, Proceedings of the 1994 Sixteenth BWEA Wind Energy Conference, Sterling, England, June 15-17, 1994. London, England: Mechanical Engineering Publications Limited; pp. 61-72.

6. Carlson O., Tsiolis, S., Johansson, G. "Variable Speed AC Drive System with Pitch or Yaw Control." Proceedings of Windpower '87, San
Francisco, CA, October 5-8, 1987. Arlington, VA: American Wind Energy Association; pp. 60-65.

7. Tangler, J.L. A Horizontal Axis Wind Turbine Performance Prediction Code for Personal Computers. An unpublished report. Golden, CO: Solar Energy Research Institute, January 1987.

8. Kelley, N.D. "Full Vector (3-D) Inflow Simulation in Natural and Wind Farm Environments Using an Expanded Version of the SNLWIND (Veers) Turbulence Code." Wind Energy 1993, Edited by S.M. Hock. SED-Vol. 14. New York: American Society of Mechanical Engineers; pp. 77-84. 